\title{
Eduardo GONZÁLEZ CALLEJA, Cifras cruentas. Las víctimas mortales de la violencia sociopolítica en la Segunda República (1931-1936), Granada, Comares, 2015. 488 pp. ISBN: 978-84- 9045-328-5
}

Cifras cruentas es un excelente trabajo de investigación que viene a cubrir una importante necesidad historiográfica. A pesar del subtítulo, el trabajo no sólo se refiere a este fenómeno histórico, sino que contempla también otras manifestaciones de la intensa conflictividad vivida en aquel momento de nuestra historia contemporánea, caracterizado, en un marco internacional, por el extremado uso de la violencia y de la radicalidad política.

La buena acogida que la publicación merece no nos impide señalar algunas deficiencias que podrían mejorar el resultado final. El libro, además de erratas poco habituales en el autor, contiene algunas redundancias que hacen pensar en un trabajo un tanto precipitado que seguramente merecería alguna reflexión más para madurar sus explicaciones y hacerlo más digerible para un público no necesariamente académico a quien, a todas luces, parecería estar dirigido. Esta puede ser una gran contradicción porque precisamente entre los especialistas gran parte de sus descripciones son ya muy conocidas y merecería tener más en cuenta una buena divulgación sobre un tema que no termina, ni mucho menos, de estar bien resuelto. Desde luego no es un libro fácil de leer ni mucho menos ameno, a pesar del gran número de tablas y cuadros que, sin duda, ayudan a una mejor comprensión. De hecho, en no pocos casos se repiten planteamientos e ideas, o se presentan los argumentos mezclados o relativamente estructurados. Un ejemplo podría ser la explicación de los parámetros con los que se ha elaborado la base de datos que mezcla su explicación con otras ideas fuerza de lo que podría ser la tesis principal del libro, como cuando explica que "los agentes de la autoridad -que a la postre serán los perpetradores de más de la mitad de las muertes- tampoco estaban preparados para tolerar ningún tipo de discrepancia sin dar cumplida respuesta arma en mano".

Tampoco ayuda mucho a la asequible lectura del texto la concatenación de párrafos tan extensos que terminan por agotar al estar cargados de argumentos y razonamientos que no se extinguen nunca. Otro ejemplo ilustrativo podría encontrarse cuando se define la violencia republicana como base legitimadora del franquismo y se trata de plantear hasta cuatro tesis que hubieran servido de explicación a la proliferación de la violencia política durante esos años. Nos encontramos con claridad la primera pero se antoja complicado descubrir las demás: "la estrategia oficial de culpabilizar al régimen republicano y a las fuerzas progresistas del desastre nacional consumado en 1936-1939", detrás del cual habría hasta un "fantasmagórico proyecto revolucionario comunista que estaría en marcha antes de julio de 1936". En el fondo se pretendía crear un "estado de necesidad" que habría 
servido para justificar el golpe de Estado de julio de 1936. Así, frente a la ilegitimidad, ilegalidad, violencia o tiranía republicana se levantaba un franquismo legitimado por la construcción de la paz, sobre todo a partir de finales de los años cincuenta y en la década siguiente.

Seguramente en lo que estaba pensando el autor en esta jugosa y necesaria introducción era en articular un discurso explicativo sobre la evolución de la violencia política desde un punto de vista historiográfico: así nos encontraríamos con la violencia política republicana como base legitimadora del franquismo; el posterior discurso equiparador del tardofranquismo y el mito de la tragedia colectiva que echaba mano de otros dos artefactos mendaces, la polarización culposa y el fatalismo antropológico característico de los españoles; la violencia como campo de estudio interdisciplinar repleto de aristas que lo hacen especialmente complejo y, por último, la irrupción con fuerza, aunque tardía, del negacionismo o el revisionismo, que ha venido a coincidir y alentar el fenómeno memorialístico.

El autor reivindica aquí, con Charles Tilly, la historia de la acción colectiva, pero en sus "propios términos" y no como una disciplina menor de la historia política, social o económica. Y más concretamente, dice, "la violencia es una atalaya privilegiada desde donde se puede otear la evolución de los diversos procesos conflictivos que afectan a una sociedad", con una producción científica de creciente relevancia, a la que Eduardo González Calleja ha contribuido de manera poderosa hasta el punto de convertirse en un consumado especialista. Se propone en estas casi quinientas páginas "una valoración preferentemente cuantitativa de la violencia sociopolítica con resultado de muerte acaecida durante la II República", aunque reconoce que "es una propuesta de análisis harto limitada, que no puede dar cuenta de la enorme complejidad, en origen, desarrollo y consecuencias, de los enfrentamientos violentos que tuvieron lugar en la época". González Calleja quiere descubrir el número, la identidad y las circunstancias de las víctimas mortales de la violencia de origen social y político porque "abordar otras formas de violencia demandaría un marco teórico más amplio y un método de análisis más complejo". Aunque alude a "otras formas de victimización" posibles que no aborda en profundidad en esta entrega. Él mismo admite una "fiebre cuantificadora" al respecto.

Entre las razones que le han llevado a hacer el libro destaca su voluntad de "avanzar en la dilucidación del debate sobre víctimas, verdugos y responsables de la violencia sociopolítica, que ya dura cerca de 75 años". La clave está en estudiar todas las muertes "con intencionalidad social o política y que tengan incidencia en el proceso de reparto de las esferas de poder", algo especialmente ambiguo porque es bien complicado determinar los acontecimientos específicos en los que se dirimía ese reparto de poder. No obstante, existen indudables líneas de continuidad desde un pasado bien conocido que, especialmente en el medio rural, pone de manifiesto una estrecha relación entre conflictividad, propiedad y tenencia de la tierra. Asimismo, resulta ya absurdo negar el obstruccionismo demostrado, incluso en los albores del régimen republicano, por la derecha más montaraz y la cúpula católica frente al reformismo acometido desde el gobierno provisional y reforzado en el primer bienio.

A los reparos que se le pueden presentar a un trabajo de cuantificación -cosa que en la práctica no es este libro o no es sólo eso ni mucho menos-, el autor se adelanta planteando su esfuerzo como "punto de partida imprescindible para efectuar otros análisis más ambiciosos que incorporen un número más amplio de variables dependientes e independientes". Se defiende ante posibles críticas con la elección de una fórmula con que poder analizar los cambios que sufrió la conflictividad político-social durante la II República, cosa que lejos de ser un tema menor, se ha convertido en el gran caballo de batalla para 
poder entender la enorme complejidad de un tiempo de enfrentamientos de paradigmas alternativos que pugnaron por primera vez con enorme fuerza en nuestro país. El autor se cura en salud con explicaciones en las que él mismo no acaba de creer, como demostrará empíricamente con sus detalladas explicaciones y descripciones: "este trabajo no tiene como propósito elaborar grandes hipótesis o formular impactantes conclusiones sobre un tema tan estudiado como la violencia en la Segunda República española. Sólo trata de describir, medir y valorar un aspecto particular de esta violencia mediante la realización de un análisis cuantitativo de los datos disponibles", nada más y nada menos que 1545 registros en una completa base de datos.

De hecho para analizar el tema se nos ofrecen explicaciones donde se demuestra un redoblado interés por el estudio de los factores sociales, políticos y culturales que pueden explicar mejor "esta peculiar relación entre víctimas y victimarios". Desde ese punto de vista, es indudable que este libro se nos antoja necesario porque supone un enorme esfuerzo por aglutinar un abigarrado número de trabajos sobre la cuestión diseminados en presentaciones de diferentes entidades y formatos, por su vocación localista en ocasiones. Como se demuestra en su extenso y completo apéndice bibliográfico. Pero además, el trabajo no adolece precisamente de falta de rigor conceptual y teórico, todo lo contrario, a la vez que se ofrece como un compendio de diferentes debates que sobre la cuestión se vienen planteando desde tiempo atrás. Precisamente, el historiador no rehúye la controversia y entra en muchos debates sin apriorismos ni militancias aunque distanciándose de falsas equidistancias.

Siguiendo en esto también a Tilly, se analizan aquí los "acontecimientos violentos como episodios políticos" vinculados al concepto de "repertorio de acción colectiva" que utiliza la sociología histórica y que permite estudiarlos para generar series temporales, espaciales o cuantitativas. Para ello, ha utilizado una buena cantidad de obras dispersas pero también anteriores balances con objetivos similares, así como un buen repertorio hemerográfico, sobre el cual advierte que se puede desprender un discurso sistemático propenso a una "estrategia de inocencia" que "desplegó la prensa conservadora respecto de la responsabilidad de los cuerpos militares y policiales".

González Calleja recuerda con George L. Mosse el concepto de "brutalización" de la política y destaca nuestros años treinta como "punto de referencia y gran divisoria entre las manifestaciones violentas anteriores y posteriores". A destacar la comparación con otros casos europeos como el alemán -1400 asesinatos políticos-; italiano -un mínimo de 1150 muertos-; o austriaco -788 muertos- que descalifica una supuesta anormalidad o patología del pueblo español. Sobre el período republicano español, las 2629 muertes registradas deben desglosarse con rigor para entender toda su dimensión. Así, no se puede soslayar el impacto de lo que conocemos como Revolución de Asturias, con 1084 muertes, lo que dejaría en 1545 la cifra de una violencia que, a su vez, debe de distribuirse entre: 540 del primer bienio, 621 del segundo -sorprende el uso de la expresión bienio rectificador, por cierto-y, finalmente, 384 que corresponderían al tiempo del Frente Popular. Se subraya la obsesión por el orden público demostrada por los diferentes gobiernos republicanos que convirtieron su gestión en uno de sus principales déficits. No en vano, la fase máxima de la violencia se produjo durante la etapa más contrarreformista. Es muy revelador, en este punto, comprobar que la conflictividad no opone, sobre todo, al capital con el trabajo, sino, en mayor medida, a los trabajadores con las fuerzas del orden y los funcionarios de la administración civil. Así, la mitad de las víctimas lo fueron por las fuerzas policiales y el sesenta por ciento de los fallecidos fueron militantes de la izquierda política y sindical, es decir, "una violencia enormemente abigarrada y dispersa en eventos de limitada participación". 
Es preciso, desde luego, poner en valor el rigor metodológico aplicado y valorar el enorme esfuerzo desplegado para llegar a conocer toda la producción historiográfica, la información en prensa, y la heterogénea documentación dispersa por tantos y tantos archivos. En definitiva, las explicaciones pluricausales aportan luz y ayudan más a la comprensión del tema de estudio. También nos obliga a olvidarnos de posturas maniqueas, equidistantes o falsamente reconciliadoras, porque la violencia sociopolítica se expresó, en efecto, a través de múltiples líneas de ruptura. No podemos dejar, por ello, de elogiar este empeño que incorpora factores "dinámicos vinculados a los instrumentos de movilización, las estrategias de acción colectiva y las estructuras de oportunidades". Sería un craso error hacerlo si consideramos que esta cuestión es "una de las más transitadas por la historia política actual -pero también por la historia social-, a un nivel de implicación profesional y de interés público sólo parangonable a la cuestión nacional". De hecho, aquella omnipresente violencia tuvo un carácter no sólo político -se desmiente rotundamente el mito de la persecución y el martirologio derechista-, sino también social -trascendental, por ejemplo, la politización de los vínculos vecinales-, laboral -distinguiendo entre conflictividad rural y urbana-, católico, regional -fundamental el estudio de la geografía de la violencia-, simbólico -hubo más anarquía que revolución-y cultural -que explica que muchas muertes lo fueron por tomarse cada uno la justicia por su cuenta en altercados espontáneos, protagonizados muchas veces por bandas de jóvenes militantes.

No es cuestión de innecesarias reivindicaciones, como historiadores que somos, sino de evaluaciones completas que nos acerquen a una mejor comprensión del pasado hecha con objetividad y rigor. Entre otras cosas, romperemos por fin con el mito de que las violencias del 36 fueron la causa de la Guerra Civil y confirmaremos la existencia del enfrentamiento entre proyectos reaccionarios, reformistas y revolucionarios que venían de tiempo atrás. 